\section{One-Pot Synthesis of Substituted Furans and Pyrroles from Propargylic Dithioacetals. New Annulation Route to Highly Photoluminescent Oligoaryls}

Chin-Fa Lee, Lian-Ming Yang, Tsyr-Yuan Hwu, An-Shuan Feng, Jui-Chang Tseng, and Tien-Yau Luh*

Department of Chemistry, National Taiwan University Taipei, Taiwan 106

Received February 8, 2000

Oligoaryl is an important class of compounds which exhibit a variety of fascinating properties for optoelectronic interests. ${ }^{1}$ Incorporation of five-membered heteroaromatic moieties into these conjugated molecules will occasionally increase fluorescence quantum yields and the optoelectronic properties of the oligomers can be tuned. ${ }^{1}$ Most syntheses of these heteroaromatic containing oligomers involve the transition-metal catalyzed cross coupling reactions of the corresponding aryl components. ${ }^{2}$ In general, the presence of a long chain aliphatic substituent in these heteroaromatic rings will increase the solubility in organic solvent and hence enhance the processibility of these materials. ${ }^{1}$ However, introduction of such alkyl substituent at $\mathrm{C}_{3}$ and/or $\mathrm{C}_{4}$ positions in these heteroaromatic rings for further cross coupling reactions is not trivial. ${ }^{3}$ Cyclization of the 1,4-dicarbonyl moiety with heteroatom-containing reagents provides an alternative procedure for the construction of these five-membered heterocycles. ${ }^{3-5}$ It is known that annulation of allenylmethanols can afford the corresponding five-membered oxygen heterocycles. ${ }^{6}$ In addition, annulation of allenyl carbonyl compounds, ${ }^{7}$ propargylic acetals, ${ }^{8}$ or oxiranes ${ }^{9,10}$ furnishes a powerful arsenal for the synthesis of substituted furans. The applications of propargylic metallic species have paved a useful path for the construction of furan skeletons. ${ }^{11}$ We recently reported that propargylic dithioacetal $\mathbf{1}$ can serve as an allene 1,3-zwitterion synthon (eq 1). ${ }^{12}$ The interesting feature for this reaction involves an umpolung of one of the two carbonsulfur bonds in the dithioacetal functionality. The organocopper intermediate $\mathbf{2}$ can react with a number of electrophiles leading

(1) Electronic Materials: The Oligomer Approach; Müllen, K., Wegner, G., Eds.; Wiley-VCH: Weinheim, 1998.

(2) For examples: Pelter, A.; Jenkins, I.; Jones, D. E. Tetrahedron 1997, 53, 10357. Pelter, A.; Rowlands, M.; Jenkins, I. H. Tetrahedron lett. 1987 28, 5213. Pelter, A.; Rowlands, M.; Clements, G. Synthesis 1987, 51. Fanta, P. E. Synthesis 1974, 9. Crisp, G. T. Synth. Commun. 1989, 19, 307. Gronowitz, S.; Bobosik, V.; Lawitz, K. Chem. Scr. 1984, 24, 5. Yassar, A.; Garnier, F. Deloffre, F.; Horowitz, G.; Ricard, L. Adv. Mater. 1994, 6, 660. Gronowitz, S.; Bobosik, V.; Lawitz, K. Chem. Scr. 1984, 23, 120.

(3) For reveiews, see: Lipshutz, B. H. Chem. Rev. 1986, 86, 795. Hou, X. L.; Cheung, H. Y.; Hon, T. Y.; Kwan, P. L.; Lo, T. H.; Tong, S. Y.; Wong, H. N. C. Tetrahedron 1998, 54, 1955 .

(4) Bean, G. P. In Pyrroles; Jones, R. A., Ed.; Wiley: New York, 1990; p 194. Jackson, A. H. In Comprehensive Organic Chemisty; Sammes, P. G., Ed.; Pergamon Press: Oxford, 1979; Vol. 4, p 296.

(5) Wynberg, H.; Metselaar, J. Synth. Commun. 1984, 14, 1. Moriarty, R. M.; Prakash, O.; Duncan, M. P. Synth. Commun. 1985, 15, 789. Nakayama, J.; Murabayashi, S.; Hoshino, M. Heterocycles 1987, 26, 2599. Asano, T.; Ito, S.; Saito, N.; Hatakeda, K. Heterocycles 1977, 6, 317. Kooreman, H. J.; Wynberg, H. Recl. Trav. Chim. Pays-Bas 1967, 86, 37.

(6) Marshall, J. A.; Wang, X.-J. J. Org. Chem. 1991, 56, 4913. Marshall,

J. A.; Bartly, G. S. J. Org. Chem. 1994, 59, 7169

(7) Marshall, J. A.; Bennett, C. E. J. Org. Chem. 1994, 59, 6110. Marshall,

J. A.; Robinson, E. D. J. Org. Chem. 1990, 55, 3450. Marshall, J. A.; Wallace,

E. M. J. Org. Chem. 1995, 60, 796.

(8) Kim, S.; Kim, Y. G. Synlett 1991, 869. Obrecht, D. Helv. Chim. Acta 1989, 72, 447. Ly, N. D.; Schlosser, M. Helv. Chim. Acta 1977, 60, 2085.

(9) Marshall, J. A.; DuBay, W. J. J. Org. Chem. 1991, 56, 1685. Marshall,

J. A.; DuBay, W. J. J. Am. Chem. Soc. 1992, 114, 1450. Sham, H. L.;

Betebenner, D. A. J. Chem. Soc., Chem. Commun. 1991, 1134.

(10) McDonald, F. E.; Schultz, C. C. J. Am. Chem. Soc. 1994, 116, 9363.

(11) Shu, H.-G.; Shiu, L.-H.; Wang, S.-H.; Wang, S.-L.; Lee, G.-H.; Peng,

S.-M.; Liu, R.-S. J. Am. Chem. Soc. 1996, 118, 530. Iwasawa, N.; Maeyama, K.; Saitou, M. J. Am. Chem. Soc. 1997, 119, 1486.

(12) Tseng, H.-R.; Luh, T.-Y. J. Org. Chem. 1997, 62, 4568. Tseng, H.R.; Lee, C.-F.; Yang, L.-M.; Luh, T.-Y. J. Org. Chem. 1999, 64, 8582.
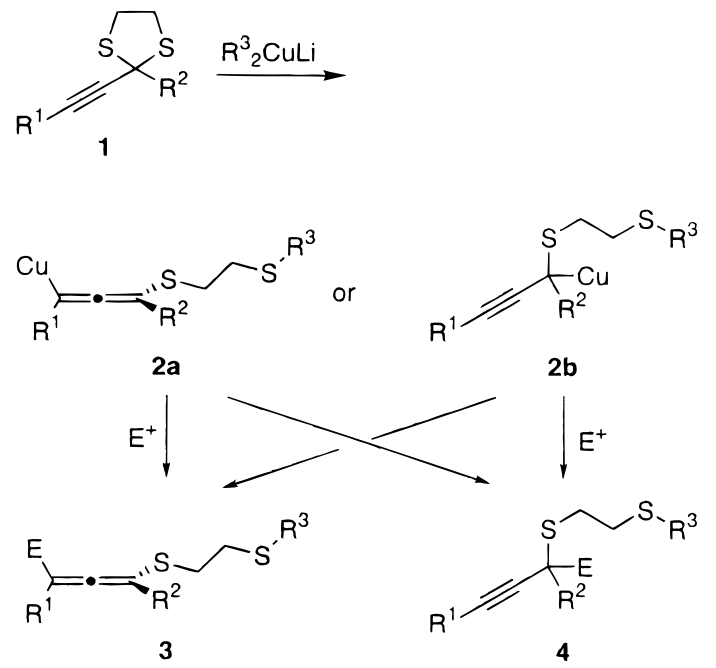

to either allenyl or alkynyl product $\mathbf{3}$ or $\mathbf{4}$. The chemoselectivity of this reaction depends on the nature of the electrophile. It is envisaged that the reaction of $\mathbf{2}$ with an aldehyde $\mathbf{6}$ or an aldimine $\mathbf{8}$ may yield the intermediate alcohol $\mathbf{5 a}$, or amine $\mathbf{5 b}$, respectively.

$$
\mathrm{R}^{4}=\mathrm{O}
$$

$$
\begin{aligned}
6 \mathbf{a} R^{4} & =\mathrm{Ph} \\
\text { b } R^{4} & =\mathrm{Et} \\
\text { c } \mathrm{R}^{4} & =4-\mathrm{X}-\mathrm{C}_{6} \mathrm{H}_{4}, \mathrm{X}=\mathrm{H}_{2} \mathrm{C}=\mathrm{CH} \\
\text { d } \mathrm{R}^{4} & =4-\mathrm{X}-\mathrm{C}_{6} \mathrm{H}_{4}, \mathrm{X}=\mathrm{CF}_{3} \\
\text { e } \mathrm{R}^{4} & =4-\mathrm{X}-\mathrm{C}_{6} \mathrm{H}_{4}, \mathrm{X}=\mathrm{CO}_{2} \mathrm{Me} \\
\text { f }^{4} & =4-\mathrm{X}-\mathrm{C}_{6} \mathrm{H}_{4}, \mathrm{X}=\mathrm{CN} \\
\text { g } \mathrm{R}^{4} & =4-\mathrm{X}-\mathrm{C}_{6} \mathrm{H}_{4}, \mathrm{X}=\mathrm{OMe} \\
\text { h }^{4} & =2-\mathrm{Furyl} \\
\text { i } \mathrm{R}^{4} & =\mathrm{PhCH}=\mathrm{CH}
\end{aligned}
$$

Since the thioether moiety in $\mathbf{5}$ could be a good leaving group, cyclization to eliminate the sulfur moiety may lead to the substituted furan $\mathbf{7}$ or pyrrole $\mathbf{9}$ (eq 2). In this communication,

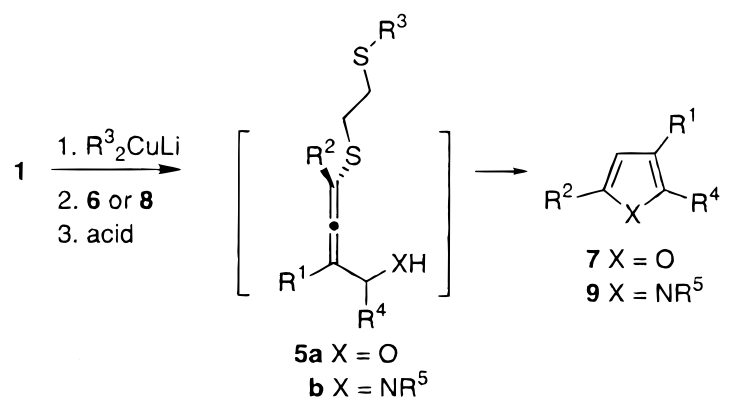

we report a convenient one-pot annulation reaction leading to furan or pyrrole moiety as a part of the oligoaryls.

A THF solution of $\mathbf{1}$ was allowed to react with 0.6 equiv of $\mathrm{Bu}_{2} \mathrm{CuLi}^{13}$ in THF at $-78{ }^{\circ} \mathrm{C}$ followed by treatment with an aldehyde 6. Without workup, the mixture was subsequently treated with trifluoroacetic acid to give the corresponding furans $\mathbf{7}$ in satisfactory yield. A range of 2,3,5-trisubstituted furans can be conveniently synthesized by this annulation procedure and repre-

(13) Less than a stoichiometric amount of the organocopper reagent (e.g. 0.6 equiv) has been used for the Michael addition of acrolein (Cf.: Matsuzawa, S.; Horiguchi, Y.; Nakamura, E.; Kuwajima, I. Tetrahedron 1989, 45, 349. See also: Lipshutz, B. H. In Organometallics in Synthesis; Schlosser, M., Ed.; Wiley: Chichester, 1994; p 298). 
Table 1. Synthesis and Properties of Trisubstituted Furans 7

\begin{tabular}{|c|c|c|c|c|c|c|}
\hline Product & $\mathrm{R}^{1}$ & $\mathrm{R}^{2}$ & $\mathrm{R}^{4}$ & $\%$ Yield & $\begin{array}{l}\lambda e m \\
(\mathrm{~nm})\end{array}$ & $\% \Phi_{\mathrm{f}}$ \\
\hline $7 a$ & $\mathrm{Ph}$ & $\mathrm{Ph}$ & $\mathrm{Ph}$ & 60 & 387 & 52 \\
\hline $7 b$ & $\mathrm{Ph}$ & $\mathrm{Ph}$ & Et & 40 & 345 & 34 \\
\hline $7 c$ & $\mathrm{n}-\mathrm{Bu}$ & $\mathrm{Ph}$ & $\mathrm{Ph}$ & 73 & 357 & 12 \\
\hline $7 d$ & $\mathrm{Ph}$ & $\mathrm{Ph}$ & & 42 & 412 & 66 \\
\hline $7 e$ & $\mathrm{Ph}$ & $\mathrm{Ph}$ & & 42 & 401 & 48 \\
\hline $7 f$ & $\mathrm{Ph}$ & $\mathrm{Ph}$ & & 45 & 417 & 50 \\
\hline $7 g$ & $\mathrm{Ph}$ & $\mathrm{Ph}$ & & 37 & 414 & 46 \\
\hline $7 \mathrm{~h}$ & $\mathrm{Ph}$ & $\mathrm{Ph}$ & & 62 & 394 & 77 \\
\hline $7 \mathbf{i}$ & $\mathrm{Ph}$ & $\mathrm{Ph}$ & & 66 & 390 & 57 \\
\hline $7 \mathbf{j}$ & $\mathrm{n}-\mathrm{Bu}$ & $\mathrm{Ph}$ & & 25 & 421 & 22 \\
\hline
\end{tabular}

Table 2. Synthesis and Photophysical Properties of Substituted Pyrroles $9\left(\mathrm{R}^{1}=\mathrm{R}^{2}=\mathrm{Ph}\right)$

\begin{tabular}{|c|c|c|c|c|c|}
\hline Pyrrole & $R^{5}$ & $R^{4}$ & $\%$ Yield & $\begin{array}{l}\lambda \mathrm{em} \\
(\mathrm{nm})\end{array}$ & $\% \Phi_{f}$ \\
\hline $9 a$ & $n-B u$ & $\mathrm{Ph}$ & 62 & 391 & 35 \\
\hline $9 b$ & $\mathrm{Me}$ & $\mathrm{Ph}$ & 64 & 393 & 35 \\
\hline $9 c$ & $\mathrm{Ph}$ & $\mathrm{Ph}$ & 73 & 395 & 19 \\
\hline $9 d$ & $n-B u$ & & 63 & 423 & 8 \\
\hline $9 e$ & $n-B u$ & & 71 & 387 & 13 \\
\hline
\end{tabular}

Table 3. Synthesis and Properties of Penta- and Hexaaryls 11

\begin{tabular}{|c|c|c|c|c|c|c|c|}
\hline Product & $-\mathrm{Ar}-$ & $\mathrm{R}^{1}$ & $R^{6}$ & $x$ & $\%$ Yield & $\begin{array}{l}\lambda \mathrm{em} \\
(\mathrm{nm})\end{array}$ & $\% \Phi_{\mathrm{f}}$ \\
\hline $11 a$ & & $n-B u$ & $H$ & 0 & 40 & $\begin{array}{l}414 \\
439\end{array}$ & 82 \\
\hline $11 b$ & & $n-B u$ & vinyl & 0 & 51 & $\begin{array}{l}437 \\
463\end{array}$ & 100 \\
\hline $11 \mathrm{c}$ & & $n-B u$ & $\mathrm{H}$ & 0 & 59 & $\begin{array}{l}419, \\
441\end{array}$ & 95 \\
\hline $11 d$ & & $n-B u$ & vinyl & 0 & 72 & $\begin{array}{l}433 \\
458\end{array}$ & 76 \\
\hline $11 \mathrm{e}$ & & $\mathrm{Ph}$ & $H$ & NBu & 28 & 423 & 65 \\
\hline
\end{tabular}

sentative examples are summarized in Table 1. Pyrroles 9 were also obtained in a similar manner when imines $\mathbf{8}$ were used in place of aldehydes. It is noteworthy that $\mathrm{BF}_{3} \cdot \mathrm{OEt}_{2}$ appeared to be a better Lewis catalyst for the cyclization in pyrrole synthesis. Results are outlined in Table 2. The structures of $\mathbf{7}$ and $\mathbf{9}$ were unambiguously assigned by NOESY, HMQC, and/or HMBC.

As shown in Tables 1 and 2 , the reaction is particularly promising to introduce a substituent at $\mathrm{C}_{3}$. More importantly, this substituent can be a long chain aliphatic moiety. As mentioned earlier, it is a common strategy to have such an alkyl group to increase the solubility for the convenience of processing leading to devices for optoelectronic investigations. Our synthesis indeed provides a very convenient entry for the synthesis of such oligoaryls or polyarylenes with these aliphatic substituents. Starting from the dialdehydes $\mathbf{1 0}$, oligoaryls $\mathbf{1 1 a}-\mathbf{d}$ having two furan moieties were obtained in one pot (eq 3). In a similar manner, when a diimine $\mathbf{1 2}$ was employed, bis-pyrrole 11e was prepared (eq 3). The results are tabulated in Table 3.
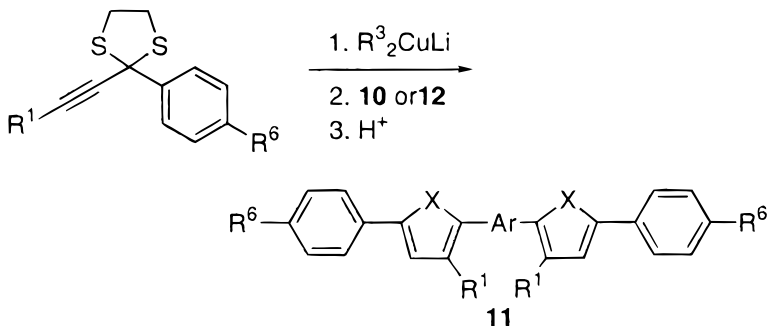

As shown in Table 1, a wide range of substituents having different functionalities remains intact under these reaction conditions. Accordingly, further modification of these functionality may lead to a variety of oligoaryls and the lengths of conjugation can thus be tuned. For example, Heck reaction of 11b with PhI afforded $\mathbf{1 3}$ in $83 \%$ yield.

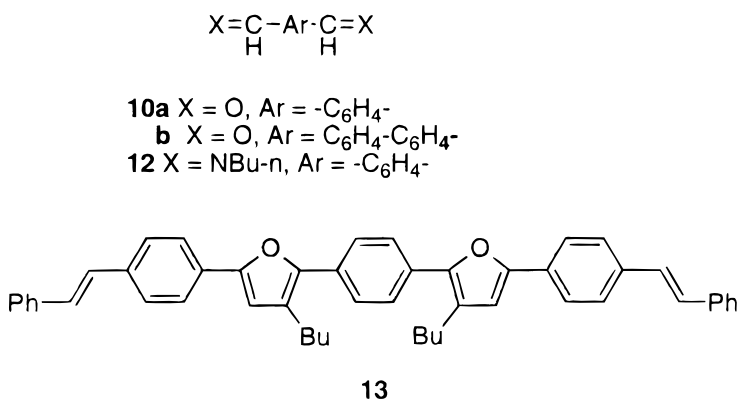

The $\lambda_{\mathrm{em}}$ values measured in EtOAc and the fluorescence quantum yields $\left(\Phi_{\mathrm{f}}\right)$ for these oligomers are also tabulated in Tables 1-3 for comparison. It is noteworthy that penta- or hexaaryl oligomers 11 (Table 3 ) exhibit very bright emission in the blue light region. As expected, the emission maximum of $\mathbf{1 3}$ $\left(\lambda_{\mathrm{em}} 460,479 \mathrm{~nm}, \Phi_{\mathrm{f}}=0.67\right)$ shifted bathochromically. Thermogravimetric analyses showed that 11c and 11d remained intact at $200{ }^{\circ} \mathrm{C}$ for at least $24 \mathrm{~h}$ and $T_{\mathrm{d}}$ values were 412 and $435{ }^{\circ} \mathrm{C}$, respectively. The potential optoelectronic applications are under investigation.

In summary, we have uncovered a useful annulation procedure starting from the propargylic dithioacetals via the corresponding organocopper intermediates resulting in a convenient synthesis of furan and pyrrole heterocycles. The reaction is particularly appealing for the preparation of a range of oligoaryls containing furan or pyrrole moieties.

Acknowledgment. This work was supported by the National Science Council and the Ministry of Education of the Republic of China.

Supporting Information Available: Experimental procedures for the preparation of $\mathbf{1}, \mathbf{7}, \mathbf{9}, \mathbf{1 1}$, and $\mathbf{1 3}$ and their ${ }^{1} \mathrm{H}$ NMR spectra. This material is available free of charge via the Internet at http://pubs.acs.org. 